\title{
ON THE ADVANTAGES
}

OF AN

\section{AMPUTATION THROUGH THE THIGH,}

\author{
EITHER AS A PRELIMINARY OPERATION TO, OR, IN SOME \\ CASES, INSTEAD OF, AMPUTATION THROUGH THE \\ HIP, WHERE THE HIP-JOINT IS ITSELF \\ DISEASED AND THE PATIENT IN \\ VERY BAD CONDITION.
}

\author{
BY \\ H. G. H O W S E, M.S. \\ Received April 12th-Read November 8th, 1892.
}

To illustrate what I have to say, it will be best to take one of the cases in which this mode of treatment was carried out. But it should perhaps be premised that the mode of treatment suggested is only to be used where all other ordinary methods have failed. Thus it is not meant to take the place of the ordinary treatment of hip-joint disease by prolonged rest, by erasion, or excision. It is, however, meant as an alternative mode of treatment to amputation at the hip-joint, where excision has been tried and has failed, or where the patient's serious

1 For much kind assistance in looking up these cases I am indebted to Mr. Lawford Knaggs, of Leeds, and to one of my former dressers, Mr. John Fawcett. 
condition manifestly does not pernit recourse to these methods.

In July, 1879, I was asked to see in consultation with Dr. Bentham, of Hackney, a lad, aged fifteen, suffering from acute tubercular osteitis of the left leg and anklejoint. There was also some vague swelling over the left hip-joint, the exact nature of which it was difficult to be quite certain of, on account of the extremely bad condition of the limb, and of the patient generally. Movements, however, of the limb caused pain in the hip-joint, -pain quite independent of that caused by the disease below the knee. The importance of this appears in the subsequent history of the case. The lad's general condition was very serious. He was extremely emaciated; there were many sinuses over the leg, which were discharging profusely; exposed bone could be felt in all the sinuses; the temperature was high, and the pulse rapid and weak. There was a bedsore over the sacrum, and a tendency to bedsore showed itself over other prominent bones. This condition had commenced three months previously, and the lad had steadily been going from bad to worse. I advised his removal to the hospital for amputation. This was done on July 25th, and the following day the leg was removed by a Stokes-Gritti amputation through the knee,-although hip-joint trouble was then existing. I did this, believing that the lad could not stand the shock of amputation at the hip-joint, and that it was possible, when the mass of diseased tissue below the knee was removed, that the hip-joint disease itself might quiet down. It would be placed, at any rate, in a very much more favorable position for cure by the natural processes, than was possible before the amputation.

It was not only the removal of the diseased tissue, however, which prompted this operation. From observation on other cases I had been led to the belief that even where hip-joint disease was the only existing lesion, amputation through the hip was not imperatively called for, and that much good might be done by amputation 
through the thigh below the disease, either at the kneejoint or just above.

In cases where only morbus coxæ existed this good was obtained-(1) by shortening the limb, and thus reducing the length of the lever, of which the fulcrum was the hip-joint, thus contributing to rest the joint; (2) by removal of a mass of tissue, which acts mainly as blood-consuming tissue, while it acts very little as bloodproducing tissue.

1. The advantages mentioned in the first heading are very great. In an ordinary case of morbus coxæ, the efforts of nature and of the surgeon are both alike directed to fixing the hip-joint, so as to render it as immoveable as possible, and thus to give it rest. Nature herself does this by spasm or rigidity of the muscles controlling the joint. This spasm is a well-known and wellmarked sign of early hip-joint disease, causing the pelvis to move with the femur when attempts are made to flex the joint. It must be apparent that very much greater muscular rigidity or spasm will be required to fix the joint, when the lever which moves it is a long one, than when it is short. Hence, nature has to bring about a much more severe and lasting spasm of the muscles controlling the hip in the one case, than the other. This very spasm is in itself probably an exhausting factor in the disease. The effects of it are shown in the "starting pains" at night, produced by partial relaxation of the muscular fibre during sleep, and then sudden and irregular contraction on any slight movement. (The nerve irritation and muscular exhaustion produced by it are probably analogous to the frontal headache, and succeeding dimness of vision, produced by ciliary spasm in a case of hypermetropia.) The surgeon tries to give the limb rest by putting it into splints and extension apparatus of divers forms and arrangement; but it must be apparent to anybody, who has watched a patient on any of these instruments for immobilising the hip, that they succeed in carrying out their intended object only 
imperfectly. From this I do not. except the plaster, leather, or poroplastic cases which surround the thigh and the body of the patient. A certain amount of play is soon permitted by all these instruments, and then every movement of the pelvis from side to side, however slight it may be, necessarily involves some motion in the hipjoint. This may easily be seen even in the best of such appliances,-I mean the Bryant double hip-splint. Hence in any critical case of hip-joint disease, any plan which makes perfect immobilisation more easy will make the chances of repair in the hip much greater.

It must be apparent that the muscles controlling the hip-joint will have much less work to do if the weight of the limb, and the length of the lever which they move, are lessened. Hence in hip-joint disease, if the limb is amputated at or just above the knee, the muscles of the hip can fix the joint with far less expenditure of muscular energy than if the limb is left intact. So great is this gain, that I have generally found in practice that no appliance to fix the hip is necessary after such amputation. The stump moves as if it were one bone with the os innominatum in every movement of the pelvis, the spasm of the hip muscles being quite sufficient to immobilise it. I have come to regard this as the most perfect form of immobilisation of the hip-joint possible.

Of course, it is not in every case that even perfect immobilisation suffices to arrest advanced hip-joint disease. So much damage may already have been inflicted that recovery is impossible. In such cases excision may be practised with success, after the amputation through the thigh (as in the case which forms the text for these remarks), if the patient possess sufficient power of recovery; or it may be necessary to proceed to the larger operation of amputation at the hip-joint, as in sundry of the other cases narrated in this paper. If excision be practised, it must be evident that the previous shortening of the limb will be a considerable help to repair, as far as immobilisation is concerned. If amputation, the patient 
has generally so far improved in condition by the previous operation, and the diminution of pain and irritation thus brought about, that he bears the operation very much better than if done in the first instance. Moreover, there can be very little doubt that the shock of removal of such a much diminished mass of tissue is very much less than the removal of the whole limb in one piece. Hence this all conduces to success in the ultimate issue of the case.

2. As regards the second heading, there will probably be more difference of opinion both amongst surgeons and physiologists. But very many years ago, while watching cases of amputation for diseased joints, the subsequent improvement in general health and nutrition seemed to me altogether disproportionate to the removal of the loss by suppuration. The improvement has usually been explained by the removal of the mass of diseased tissue, and thus the cessation of processes of disease (e.g. high temperature, \&c.) inconsistent with healthy nutrition. Such, in fact, is no doubt the explanation of a great deal of the improvement, but it does not take place after excision or arthrectomy to anything like the same extent, though the removal of the diseased tissue should be in the one case as complete as in the other. Hence I was led to the belief that the mere cutting off of the limb (i.e. of so much healthy tissue, which uses up the blood more than it forms it) is a more probable explanation. With this view I have amputated through the knee in sundry cases of pure hip disease, and I believe that the improvement shown by the patient in some of the cases narrated subsequently must be attributed to this cause.

Returning to the case which forms the subject of this paper, the temperature fell to normal for a few days after the amputation, but then showed a tendency to rise, especially in the evening, so that while the morning averages were about normal, the evening varied from $100^{\circ}$ to $102^{\circ}$ Fahr. Nevertheless a very great improvement took place in the boy's health. He took his food better, slept better, improved in nutrition, and the sacral bedsore 
healed considerably. For some time we were in hopes that the hip would quiet down and anchylose. But suppuration occurred in the stump, and abscesses were opened on August 13th and September 11th. It was for some time doubtful whether these abscesses were connected with the stump or with the hip. The subsequent history showed that they were most probably connected with the hip, and on October 7th, grating on movement being now very distinct in the joint, I excised it. I ventured to do this, believing that the gain in the lad's strength since the amputation was sufficiently great to justify it.

The improvement which followed the excision was very great. The temperature fell to normal; he steadily gained in strength and weight, and finally left the hospital on June 20th, 1880. He has remained quite well since, and has been often seen and heard of.

Reviewing the case and the possible alternative lines of treatment at the different stages, amputation of the hipjoint when the patient was first seen, which many surgeons would have considered the only justifiable line of treatment, would most likely have proved fatal in his then extremely precarious condition. Moreover, even if successful, it would have left the patient without a good stump to fix an artificial leg to. Excision of the hip was of course out of the question while the mass of tubercular necrosed bone remained about the leg. Secondly, after the leg had been amputated successfully, amputation at the hip (instead of excision) would again have left the patient with a shorter and inferior stump to that which he at present possesses.

The advantage, therefore, to the patient of this line of treatment is that he now has a stump, upon which he can wear an artificial leg of very much greater utility than anything possible, supposing the limb to have been amputated at the hip, and that he is now alive and well, whereas any other line of proceeding would have immeasurably increased the risks to his life.

It is clear that this method of treatment must be appli- 
cable in a much wider class of cases than the one just described. Thus, of the succeeding cases, the first is one of pulpy disease of the left knee ; this was excised, and during the rather tedious convalescence pulpy diseuse of the right hip, i. e. of the hip on the opposite side, showed itself. The left leg was accordingly amputated through the lower third of the thigh, with the result that the hip quieted down, and he left the hospital with the stump healed, and with no pain on pressure over the hip. He remained at home a twelvemonth, when signs of hip-joint mischief recurred. He came into hospital again, and had the hip-joint excised; this healed and he did well. This case is believed to be an example of advantage No. 2, $i$. e. the cutting off of a mass of blood-consuming tissue, the great improvement in health thereby resulting, so that the opposite hip-joint disease became quiescent.

In the two succeeding cases (Group II) Case No. 3 is the one which forms the text of this paper. Case 2 is a very similar one. It is a case of hip-joint disease and acute necrosis of the left fibula. The leg was amputated above the knee-joint; the hip-joint quieted down after this amputation, and he left the hospital with the joint apparently firmly ankylosed. He showed himself two years after. A sinus had broken out over the hip and at times discharged rather freely, but apparently he did not find it very inconvenient, for he did not apply for treatment, and I have not seen him since. It may be a question in this case whether the amputation should not have been followed by an excision of the hip, but when he left the hospital there seemed to be no need for such an operation.

In Cases 4 and 5 (Group III) we have patients admitted for hip-joint disease, in whom excision was performed but failed to arrest the disease ; amputation above the knee on the same side was consequently performed, with the result that the excised hip-joints healed and the patients convalesced.

In Cases 6, 7, and 8 (Group IV) we have patients all of whom subsequently underwent some form of amputa- 
tion at the hip-joint. They are cases in which the primary amputation at the hip-joint would have been inapplicable, either from the likelihood of the amputation terminating fatally, or from the case not appearing at first sufficiently serious to warrant its performance. Of the three patients in this list Case 6 comes into the second category; Cases 7 and 8 come into the first. Thus Case 6 was admitted for hip-joint disease, which was excised. Unfortunately she developed scarlet fever shortly after the operation, and had it severely; this damaged the healing of the operation wound, and some caries resulted. She steadily lost ground and became excessively emaciated and weak, the limb itself becoming perfectly useless. As amputation at the hip would probably at this time have proved fatal, a Stokes-Gritti amputation at the knee was performed. She now grew much stronger, but the hip remaining useless and the sinuses not healing, amputation at the hip was performed with perfectly satisfactory results. Case 7 was a young man with phthisis, melancholia, and tubercular disease of the hip. He was in an excessively emaciated and anæmic state, and amputation at the hip would have been almost certainly fatal. A Stokes-Gritti amputation at the knee was therefore first performed. His health now greatly improved, but the hip disease remained active. His general condition appearing to preclude excision, the remainder of the limb was removed at the hip-joint. This entirely healed, and he went home greatly improved in general health. For a time also his mental condition was much more satisfactory, but he gradually relapsed in this respect, and when I last heard of him he was in an asylum, his hip remaining healed. Case 8 was a man, aged twenty-nine, who had developed hip-joint disease at five years of age. For this he was under treatment for two to three years. Subsequently he appeared to get well enough to get about upon it, though the hip-joint was probably permanently damaged at this time. About 1880, and for various years subsequently, abscesses formed 
about the hip, and for fifteen months before admission he had been entirely confined to bed. On admission there was probable lardaceous disease of both liver and kidney $(i . e$. the liver was much enlarged, and the urine was very albuminous); there were also many sinuses about the hip and rectum. The limb was first amputated just above the knee, and afterwards at the hip, but the head of the femur was too firmly ankylosed to the pelvis for complete removal. He improved greatly after the amputations; the liver returned apparently to its normal size, and the albumen disappeared from the urine. After leaving the hospital he was well enough to return to work for a while, but the disease about the os innominatum was too extensive for perfect healing, and sinuses still persisted, for which he has lately again come under treatment.

Cases 9, 10, and 11 were patients in whom a fatal ending occurred. Excision or amputation through the thigh was done in all; amputation through the hip in two. All the operative procedures were carried out in safety. Death resulted in all from previous lardaceous or general tubercular disease.

It will thus be seen that this principle of treatment is applicable in a rather wide class of cases, and it is probable that further experience will enlarge the number. For example, it will probably prove applicable in multiple joint disease (mostly of a tubercular nature), affecting joints of the upper extremities as well as of the lower. All surgeons know how unsatisfactory such cases are to treat, and how often they terminate fatally, either from general tubercular or from lardaceous disease. It will probably be found that the sacrifice of a portion of one of these affected limbs so far improves the general health, that the other affected joints will become amenable to surgical treatment.

The following eleven cases of amputation near the knee in patients suffering from hip disease have all occurred in my wards at Guy's Hospital.

They are arranged in five groups.

voL. LXXVI. 


\section{GrodP I.}

1. Pulpy disease of left knee; excision; disease of right hip; amputation through left thigh; recovery ; subsequent relapse; excision of right hip.-A. W., æt. 5 (Dorcas), was admitted October 13th, 1878, with pulpy disease of left knee. It was excised on December 13th, and the after-progress was tedious. On February 24th, 1879, signs of disease in the right hip were noticed for the first time, and the knee wound was still discharging considerably. Amputation through the left thigh was performed on March 22nd. There was still pain in the right hip on the 31st, but by April 23rd it had vanished. On May 31st the stump was healed, and pressure over the right hip caused no pain, and the health was much improved. He left the hospital on August lst.

He was readmitted on June 15th, 1880, for a relapse of the disease in the right hip. This was excised and he did well.

\section{GROUP II.}

2. Destruction of the left hip ; acute necrosis of left fibula ; amputation above knee-joint; improvement of hip disease; ankylosis; subsequent sinus.-A. P., æt. 14 (Naaman), was admitted April 13th, 1879, with an acute illness of two days' duration. Active delirium; temp. $104^{\circ}$. The left hip was evidently acutely diseased. Bryant's line on the left side measured $1 \frac{5}{8}$ inches, and on the right $2 \frac{5}{8}$ inches; and the left trochanter was much thickened. On May 4th the left leg was found swollen, and fluctuation was detected. It was incised, and the whole fibula found bare. On June 16th the patient was much wasted, and there was still much pain in the hip and knee. On the 22nd Gritti's amputation was performed at the knee-joint. The hip trouble quickly subsided, and on September 20th it is noted that the hip was firmly ankylosed. On November 21 st he was discharged on crutches with no pain in the hip.

He came to the hospital on March 27th, 1881. "A sinus connected with the hip had appeared some time after he went home, and at times discharged freely."

3. Acute necrosis of tibia; amputation above knee; acute suppurative hip disease; excision; recovery.-W. W., æt. 15, was seized suddenly in April, 1879, with acute pain in the left leg; matter formed and was let out, and he was admitted on July 25th with the left tibia and ankle-joint far advanced in a condition of necrosis. There was no albuminuria; the liver was large, and he had bedsores. There was also some swelling about the left hip-joint, which was thought to be pulpy, 
but the general condition was so bad that it was difficult to make out the exact state of the joint. Stokes-Gritti's amputation was performed on the 26th. On August 2nd the stump was doing well, but the temperature rose to above $100^{\circ}$ and acute suppurative disease of the hip (left) set in, abscesses being opened on August 13th and September 11th. On October 7th the hip was excised and much pulpy material removed. From this time the boy's health rapidly improved.

He left the hospital on June 20th, 1880, and remains well to the nresent time. $\mathrm{He}$ is often heard of.

\section{GroUP III.}

4. Left hip disease; strumous manifestations in other joints and fingers; excision; Gritti's amputation; convalescence.-S. S., æt. 7 (Dorcas), was admitted in August, 1879, with disease of the left hip of six months' duration. There was thickening of the tissues around the metacarpals of both right and left hands, and around the right elbow. There was some effusion into the right knee. Sinuses were freely laid open on October 7th. The hip was excised on November 14th. After this the notes were very inadequate; but on March 9th, 1880, the left leg was removed by Stokes-Gritti amputation. Then the patient improved greatly in health; the sinuses quickly granulated up, and on May 8th she was discharged with instructions to return to hospital if she did not get quite well. There is no note of her having been up to hospital since.

5. Suppurative hip disease; excision; progressive emaciation; Gritti's amputation; convalescence.-F. G., æt. 15 (Naaman). Disease of the left hip began in January, 1881. It was treated by ordinary methods till September, 1882. On the 18th October, 1882, he was admitted into Guy's, when suppuration had occurred. On October 20th the abscess was opened and the hip excised. On December 12th another abscess opened spontaneously below Poupart's ligament. Though the sinuses discharged but little the patient failed to improve, and remained much emaciated. On December 20th Gritti's amputation at the knee was performed. On January 1st his general condition was much improved. On the 16 th the stump was healed, and he continued to gain flesh and strength. He was discharged on March 7th, on crutches, and the sinuses were noted as being very nearly healed. There had been no albuminuria. 


\section{Group IV.}

6. Left hip disease; excision; progressive advance of disease for three and a half years; Gritti's amputation; amputation at the hip six weeks later; spinal trouble; recovery.-N. S., æt. 22 (Charity), was admitted March 19th, 1879, for left hip disease. Excision was performed in October. She developed scarlatina within the first fortnight, and this damaged the healing of the wound, so that some necrosis occurred about the os innominatum, and small pieces of bone came away. She went home, but in March, 1881, she was readmitted, and sinuses about the hip were explored and scraped out. From this time till 1883 she had to lie on a couch, and bone continued to come away.

She was readmitted January 22nd, 1883, with the left leg pendulous, inverted, shortened, and useless, with scars that were healed over but still tender, and with loss of sensibility below the knee. On February 2nd Stokes-Gritti's amputation was performed to improve the patient's general condition, and shorten the lever of the useless leg. After the operation the hip was easier, but the stump gaped when the sutures were removed, and was not healed till April 13th. She then was able to sit up. Subsequently she suffered great pain in the hip, and on May 29th Furneaux-Jordan's amputation was performed, She was discharged quite healed on July 14th.

She was readmitted for a doubtful spinal condition on April 23rd, 1884. She was greatly improved in condition, being plump and well nourished. There was occasionally a little discharge from the inner side of the stump. For this she was ordered to wear a Sayre's jacket. She has continued to wear these and poroplastic jackets ever since (the plaster jacket, however, giving the greatest comfort). With this support she is able to get about fairly actively and perform ordinary household duties. She writes, February, 1892, that the hip is quite well, but her spine gives her a good deal of trouble.

7. Phthisis; left hip disease; suppuration; incision; amputation through lower third of thigh; amputation at hip; recovery.-L. P., æt. 28 (Naaman). In September, 1880, Dr. Douglas Powell diagnosed phthisis.

On February 15th, 1886, he was admitted into Guy's. He then had early disease of the left hip, and was kept in a Bryant's splint four months. He was admitted to Naaman on May 29th. In October abscess had formed, and there was half an inch shortening. Amputation through the lower third of the femur was performed on November 2nd, and the abscess over the hip opened. The stump healed by November 24th, but there was a good deal of discharge from the hip, and on December 7th 
the limb was amputated at the hip. The stump healed well, but another abscess formed and was opened, and erentually he was discharged to a convalescent home on July 2nd, 1887, with the stump quite healed, and all the sinuses closed. This patient had been melancholic for some time before admission. He remained so throughout his stay in the hospital, but improved greatly after the operations towards the end of the time. He continued to improve after his return home, and was able for some time to return to work ; but he finally relapsed, and was last heard of in a lunatic asylum, though the stump remains healed.

8. Right hip disease; prolonged suppuration; phthisis ; lardaceous disease; rectal fistula; amputation through thigh; tedious afterprogress; removal of rest of femur ; convalescence.-E. H., æt. 29 (Naaman). Hip trouble began when he was five, after a fall from a perambulator. Extension was applied for eight months in St. Thomas's Hospital, and he was subsequently manipulated by Hutton the bonesetter. He got about quite well till 1880 , and in $1880,1886,1887$, and 1888, various abscesses formed about the right hip, and were opened. He had been in bed fifteen months before admission to Guy's on September 20th, 1889.

The right hip was then dislocated and ankylosed on the dorsum ilii ; there were discharging sinuses and a rectal fistula. The liver and spleen were enlarged, and the urine contained 1.05 grammes per litre of albumen. There was old phthisis at the left apex, and recent at the right, and the temperature was hectic.

On October lst the thigh was amputated through the lower third. The progress after this operation was tedious and anxious. There was frequent secondary hæmorrhage, owing to an exceedingly fotid abscess having been cut across in the amputation. This poisoned the stump in spite of all antiseptics, and produced septic osteo-myelitis. The end of the femur necrosed and protruded from the stump. Two inches more of the bone had to be removed, and the wound eventually to be plugged and dressed under $\mathrm{CHCl}_{3}$.

$\therefore$ By October 28th he was gaining ground.

On November lst the rectal fistula was operated upon, and on November 11th he was sitting up. From this time till March 28th, 1890, there were several minor operations upon both hip and rectal sinuses. The liver diminished in size.

On May 9th the shaft of the femur was found in a diseased state, and was dissected out. An old sinus near Poupart's ligament broke out on August 6th, but on the 22nd the wounds were granulating and there was no discharge. On the 23rd he was discharged to a convalescent home. 
Throughout the case albumen was rarely absent from the urine; from 1 in 1000 it diminished to a "trace," a "slight trace," and a "very slight trace," and the diminution in the size of the liver was very marked.

\section{GROUP V.}

9. Left hip disease ; sinuses ; excision ; lardaceous disease; amputation through thigh; amputation at hip; death from lardaceous disease.-M. S. When three years old disease of the left hip began after a fall. She was treated at St. Thomas's in 1871, and in 1872 at Guy's, with rest. Suppuration occurred, and she was readmitted to Guy's, and the abscess opened and the separated epiphysis removed on October 11th, 1872. She remained well till 1885, when there was a relapse following injury. The trochanter and neck were excised. After leaving the hospital the disease was aggravated by another fall. She was readmitted in November, 1885, and had then excessive lardaceous disease of viscera. The urine became nearly solid on boiling. Amputation through the lower third of the femur was performed to shorten the lever. The stump healed, and the patient left the hospital on February 3rd, 1886.

She was readmitted in March, the discharge from the hip becoming more troublesome. The lardaceous disease was unaltered, but the patient's general condition was improved. On May 7 th the limb was amputated at the hip and the acetabulum found bare. She did well till six days before she died, and the stump healed, but on May 28th she began to have pain in the back, was sick, and refused to take food; became sleepy and hardly took notice of any one, and died on June 1st.

Post-mortem.-There were scattered tubercles at each apex. Acute pericarditis. Very extensive progressive disease of the pelvis and extensive lardaceous disease of the spleen, kidney, liver, and intestines.

10. Left hip disease; albuminuria; amputation through thigh; excision; amputation at hip; prolonged suppuration; death.-W. W., æt. 17. When two years old he attended at Guy's for hip trouble following a fall, and was discharged "cured." He went away till April, 1880, and could flex the joint to a right angle. In April an abscess formed in the groin, and he left work. He was admitted on April 27th, 1880 , with active disease of the left hip, with dislocation of the head on to the dorsum ilii, two copious discharging sinuses, and slight albuminuria.

On September 10th amputation through the thigh was performed, and 
a large abscess opened over the hip. On October 5th a hip abscess was again incised, and the joint found partly ankylosed. Excision was performed on October 26th, and the finger passed into the pelvis in two places. Notwithstanding the profuse discharge, occasional diarrhœa, and albuminuria, the patient gained flesh fast. On January 4th, 1881, amputation at the hip was performed, and the stump healed fairly well. There was still much discharge, yet he improved, and in May was getting up. During the summer his condition fluctuated, but the profuse discharge and a hectic temperature gradually reduced his strength, and eventually he sank into a comatose state, and died on September 13th.

No post-mortem report.

11. Right hip disease with sinus; amputation through thigh; excision of hip ; lardaceous disease ; old and recent tuberculosis ; death.S. S., æt. 44, an old soldier, was admitted on October 2 nd, 1887, with the right knee acutely flexed and the hamstring muscles contracted. The right hip was flexed and fixed, and there were marks of old sinuses. Three times under ether forcible extension was made and the knee straightened.

There was occasional discharge from the hip sinus. In January and February unhealthy sores formed along the leg, probably due to the splint; the limb became very painful and the patient's condition bad.

On February 27th the leg was amputated above the knee, as he was not in a state to stand amputation at the hip. On March 10th the wound was nearly healed, and the hip was excised on the 23rd and found full of pus. This was followed by profuse discharge, bedsores, and sweats. The urine contained one ninth of albumen. In May necrosis of the sacrum from a bedsore occurred. In June he grew weaker, and the abdomen became distended, and death took place on the 15th.

Post-mortem.-There was extensive tubercular disease of femur and pelvis ; tubercular peritonitis and old tubercle of the lung; lardaceous disease of the kidneys, liver, spleen, and intestines.

In Group I the amputation and the hip disease were on different sides. The result is an illustration of the way in which, in tubercular disease of more than one joint, the general health may be so greatly benefited by the removal of one exhausting focus that the remaining disease may go on to cure.

This case may be compared with the two cases in the next group in which the limb was shortened on the affected side before excision of the diseased hip was performed. In the first of these two cases (Case 2) the hip ankylosed after the excision, and though he showed himself subsequently at the hospital with a discharging sinus, he did not ask for any 
subsequent treatment. In the second case (Case 3) subsequent excision became necessary, and the most satisfactory results were obtained.

There can hardly be a doubt that the facilities which the shortening of the limb gave for a less irksome and confining treatment contributed considerably to the satisfactory results.

Group III includes Cases 4 and 5. Excision was first performed in both cases. In one after two months' interval the patient remained emaciated and unimproved; in the other after four months the necessity for further operative treatment was held to exist, but the patient's state cannot be described in consequence of the absence of notes at this period. In both cases Stokes-Gritti's amputation was performed, and was followed by greatly improved health and convalescence, which, as neither case has reappeared, it is possible to hope has been permanent.

Group IV contains three cases in which the whole limb was removed by instalments. In Case 6 the disease was severe and of long standing. In Case 7 the disease was rapid and the patient was phthisical; and Case 8, with phthisis, lardaceous disease, and rectal fistulæ, was an unusually bad and unpromising case. But two left the hospital to all appearances cured, and the third convalescent.

Group V includes three fatal cases. In all there was extensive disease of the pelvis and lardaceous disease. The operative procedures were carried out in safety and did well, but death resulted from the lardaceous disease in two instances, and in the third from lardaceous disease and other tubercular lesions.

(For report of the discussion on this paper, see 'Proceedings of the Royal Medical and Chirurgical Society,' Third Series, vol. v, p. 15.) 